\title{
Força de preensão manual em atletas de Jiu-Jitsu brasileiro: estudo comparativo entre graduações
}

\author{
Handgrip strength in brazilian Jiu-Jitsu athletes: comparative study \\ between graduations
}

Guilherme da Silva Gasparotto1,2, Edson Marcelo da Silva Lopes Junior², Ragami Chaves Alves', Rubens Batista dos Santos Junior ${ }^{-1}$, João Carlos Alves Bueno', Tácito Pessoa de Souza Junior ${ }^{1}$

Universidade Federal do Paraná (UFPR), Curitiba, PR, Brasil.

zInstituto Federal do Paraná (IFPR), Pinhais, PR, Brasil.

Recebido em: abril 2015 / Aceito em: setembro 2015

guilhermegptt@gmail.com

\section{RESUMO}

Objetivo: comparar a força dos músculos flexores do punho entre graduações de atletas de Jiu-Jitsu brasileiro, previamente e imediatamente após combate, em competição oficial. Método: para medida da força dos músculos flexores do punho foi utilizado dinamômetro. A medida foi expressa em $\mathrm{Kg}$ e comparada entre faixas etárias e graduações. Foram realizadas duas medidas de preensão manual com cada atleta, uma anteriormente o primeiro combate e a segunda medida imediatamente após a luta. Resultados: verificou-se redução da força de preensão manual, expressa em média de $\mathrm{Kg}$, após o combate, entre atletas das três categorias de idade, 18 a 23 anos ( $p=0,02), 24$ a 29 anos $(p=0,03)$ e 30 anos ou mais ( $p=0,01)$. Porém, entre as categorias de idade não se observou diferença na média de força de preensão pré luta $(p=0,31)$ e preensão pós luta $(p=0,22)$. Comparado aos atletas faixas branca, os faixas azul obtiveram redução de força, em média de 6,16 Kg. No entanto, a maior variação foi observada entre os atletas faixa roxa $(11,7 \mathrm{Kg})$. Considerações finais: verificou-se importante diferença na força de preensão manual antes e imediatamente após combate de atletas de Jiu-Jitsu brasileiro, graduados nas faixas azul e roxa, independente da faixa etária.

Palavras-chave: Artes Marciais; Força muscular; Atletas.

\section{ABSTRACT}

Objective: compare the handgrip strength between levels of Brazilian Jiu-Jitsu athletes, before and immediately after an official competition combat. Methods: a dynamometer was used to measure the handgrip strength. The measure was expressed in $\mathrm{Kg}$ and compared between age groups and graduations. Two measures of handgrip strength were performed in each athlete, the first one before the first combat and the second one just after the fight. Results: it was found reduction of handgrip strength, expressed as a $\mathrm{Kg}$ average, after the combat among athletes of three age categories, 18 to 23 years ( $p=0.02), 24$ to 29 years $(p=0.03)$ and 30 years or more $(p=0.01)$. However, between the age groups there was no difference in the handgrip strength average pre-combat $(p=0.31)$ and post-combat ( $p=0.22)$. When compared to the white belt athletes, the blue belt ones had a reduction of strength averaging $6.16 \mathrm{Kg}$. But the greatest handgrip strength variation was observed in the purple belt athletes $(11.7 \mathrm{Kg})$. Closing remarks: there was relevant difference in handgrip strength before and immediately after a combat of Brazilian Jiu-Jitsu athletes, graduates in blue and purple belts, regardless of age group.

Keywords: Martial Arts; Muscle strength; Athletes.

\section{INTRODUÇÃOO}

O sucesso no esporte contemporâneo se caracteriza cada vez mais pelo aprimoramento das capacidades físicas do atleta, principalmente em modalidades individuais, cujas técnicas são amplamente difundidas. ${ }^{1}$ Associado à velocidade que a informação chega a diferentes regiões do mundo, devido ao avanço tecnológico, a popularização de determinado esporte contribui 
para intercâmbio de treinadores e consequentemente da expansão do conhecimento técnico a respeito de tal modalidade. Este processo diminui diferenças de rendimento associado à capacidade técnica e aumenta a responsabilidade das capacidades físicas como determinantes deste processo. ${ }^{2,3}$

As artes marciais passam por processo de popularização intensa, principalmente no que diz respeito às principais modalidades que compõem a luta de Artes Marciais Mistas (MMA). Por meio de eventos televisivos, estas modalidades chegam a regiões diversas no mundo, e diferente do que se observava há décadas atrás, é possível verificar que a capacidade técnica dos atletas de alto nível encontram-se similares. Diante disto, é comum observar combates decididos em virtude de diferenças nas capacidades físicas dos competidores. ${ }^{4}$

Entre as modalidades de combate difundidas atualmente, se encontra o Jiu-Jitsu brasileiro, que tem como principais fundamentos técnicos as projeções, imobilizações, chaves em alavancas, torções e estrangulamentos; ${ }^{5}$ em grande parte destas técnicas há intensa demanda de pegadas no dogi. ${ }^{4}$ Todas estas técnicas, em algum momento de execução, demandam contração dos músculos flexores do punho. Como resultado da utilização intensa deste mecanismo biomecânico, Borges Junior et $a^{6}{ }^{6}$ sugerem que lutadores de Jiu Jitsu brasileiro apresentam maior força de preensão manual comparado com outras modalidades de lutas, como Judô e Aikido.

Diante disto, sugere-se que a repetição intensa, durante uma sessão de treinamento ou competição, poderia gerar desgaste muscular determinante para desfecho do combate. Todavia, é possível que a experiência ou tempo de prática do competidor possa interferir no desgaste provocado durante o esforço repetido, no que tange evitar contrações desnecessárias e economia de energia. ${ }^{7,8}$

Pesquisas com atletas de Artes Marciais são comumente realizadas sob a perspectiva de se analisar variáveis metabólicas ou capacidades de força pura, potência associadas ao rendimento. Diante da demanda da flexão dos músculos do punho na modalidade Jiu- Jitsu brasileiro, esta capacidade poderia ser aprofundada, na tentativa de entendê-la como determinante do rendimento do atleta. Apesar de algumas pesquisas serem conduzidas com atletas lutadores, grande parte destes estudos é realizada em sessões de treinamento ou simulacros de competição, o que compromete resultados de variáveis relacionados ao esforço, devido à impossibilidade de submeter o atleta às condições de estresse da competição, consequentemente ao esforço máximo. ${ }^{9,10}$

Diante do exposto, o objetivo foi comparar a força dos músculos flexores do punho entre graduações de atletas de Jiu-Jítsu brasileiro, previamente e imediatamente após combate, em competição oficial.

\section{MATERIAIS E MÉTODO}

O estudo foi conduzido com atletas da modalidade de Jiu-Jitsu brasileiro, durante a terceira etapa do campeonato estadual paranaense, ocorrido na cidade de Curitiba, em setembro de 2013. A amostra selecionada por conveniência foi composta por competidores com idades entre 18 e 36 anos, com graduações de faixas branca, azul e roxa. Para a realização das análises, a idade foi categorizada em 18 a 23 anos, 24 a 29 anos e 30 anos ou mais. Nas competições oficiais, os atletas são definidos como "Masters", quando com idade igual ou superior a 30 anos. Idades inferiores a 30 anos são categorizados como "Adultos". Neste estudo, os atletas "Adultos" foram divididos novamente, na tentativa de se amenizar a influencia do fator idade nas análises. Assim, seguiram-se as categorias de idade anteriormente mencionadas.

Inscreveram-se nesta etapa do campeonato 102 atletas adultos, entre as três graduações. Todos foram convidados a participar do estudo conduzido por pesquisadores do departamento de Educação Física da Universidade Federal do Paraná. Ao final, a amostra total foi de 52 lutadores.

A presente pesquisa foi aprovada pelo Comitê de Ética em Pesquisa com seres humanos do setor de Ciências da Saúde da Universidade Federal do Paraná, estando de acordo com a resolução n. 196/1996 do Conselho Nacional de Saúde, sob o registro CAAE: 34134514.6.0000.0102, parecer 758.403.

\section{Instrumentos e Procedimentos}

Para a medida da força dos músculos flexores do punho foi utilizado dinamômetro JAMAR ${ }^{\circ}$. O instrumento é amplamente utilizado por profissionais da área de desempenho físico ou reabilitação. ${ }^{11} \mathrm{O}$ dinamômetro possui duas alças paralelas, sendo uma fixa e outra móvel, que pode ser ajustada em cinco posições diferentes, propiciando um ajuste ao tamanho da mão do indivíduo. Este aparelho contém um sistema hidráulico fechado que mede a quantidade de força produzida por uma contração isométrica aplicada sobre as alças e a força de preensão da mão é registrada em quilogramas ou libras.

Foram realizadas duas medidas de preensão manual com cada atleta. A primeira foi realizada anteriormente ao primeiro combate do competidor e a segunda medida imediatamente após sua saída da luta.

\section{Análise Estatística}

A variação da força pré-competição e pós-competição foi obtida pela diferença da medida inicial e final. A variação positiva indicou aumento da força da primeira para a segunda medida e uma variação negativa indicou redução da mesma após o combate.

A medida de força foi expressa em $\mathrm{kg}$ e descrita por meio de medidas de tendência central (média) e dispersão (desvio padrão), além da apresentação dos valores mínimos e máximos. A normalidade dos dados foi confirmada mediante teste de Kolmogorov Smirnov. A diferença entre os valores médios da preensão manual antes e após o combate, para cada faixa etária e graduação foi testada por meio do teste $t$ para medidas repetidas. Para verificar a diferença das médias, pré e pós combate, entre as faixas etárias foi realizada análise de variância ANOVA. Este teste também foi realizado para verificar a diferença na variação da força entre as diferentes graduações (faixas branca, azul e roxa). Para identificação das diferenças foi aplicado Post Hoc de Tukey. O nível de significância foi estipulado em $\mathrm{p}<0,05$. 
Tabela 1 - Comparação dos valores de preensão manual entre as faixas etárias para as medidas pré e pós combate e entre as medidas pré e pós, dentro de cada faixa etária.

\begin{tabular}{|c|c|c|c|}
\hline Faixa etária (n) & Preensão pré média (dp) & Preensão pós média (dp) & $\mathbf{p}$ \\
\hline & $p=0,31$ & $p=0,22$ & \\
\hline $18-23$ anos (24) & $44,74(2,69)$ & $39,49(3,57)$ & $0,02 *$ \\
\hline 24-29 anos (15) & $41,48(3,81)$ & $37,13(4,82)$ & $0,03 *$ \\
\hline 30 anos ou mais (18) & $41,63(2,41)$ & $35,69(2,78)$ & $0,01 *$ \\
\hline
\end{tabular}

DP: Desvio Padrão; Teste $t^{*} ; F=1,83$.

Tabela 2 - Comparação da força de preensão manual pré e pós combate para cada graduação e da variação de força entre as graduações.

\begin{tabular}{|c|c|c|c|c|c|c|}
\hline \multirow[b]{2}{*}{ Grupos } & \multirow[b]{2}{*}{ Preensão pré } & \multirow[b]{2}{*}{ Preensão pós } & \multirow[b]{2}{*}{$\mathbf{p}$} & \multicolumn{3}{|c|}{ Variação de força } \\
\hline & & & & média (dp) & $\min$ & máx \\
\hline \multicolumn{7}{|c|}{ Graduação faixa (n) } \\
\hline branca (18) & $40,13(2,45)$ & $41,13(2,68)$ & 0,67 & $1(1,19)^{a}$ & -2 & 8 \\
\hline azul (15) & $46,31(3,32)$ & $40,71(4,92)^{*}$ & 0,02 & $-6,16(1,08)^{b}$ & -1 & -12 \\
\hline roxa (20) & $41,41(3,52)$ & $30,47(3,93)^{*}$ & 0,001 & $-11,7(2,1)^{\mathrm{c}}$ & -6 & -24 \\
\hline
\end{tabular}

Teste $t^{*} ; F=8,31: c>a, b ; b>a$.

\section{RESULTADOS}

Entre os 102 competidores convidados a participar do estudo, 52 realizaram a coleta de dados (51\%). A média de idade dos atletas foi de $23( \pm 4,1)$ anos.

Foi possível verificar redução nos valores de força de preensão manual, pré combate e pós combate, entre os atletas nas três categorias de idade. Porém, não se verificou diferenças destas medidas, nas médias de força em $\mathrm{kg}$, entre as categorias de idade (tabela 1).

Verificou-se que com o aumento da graduação (faixas azul e roxa), houve aumento da variação de força dos flexores do punho. Sendo que, quanto maior a graduação do atleta, maior foi a redução de força após o combate (tabela 2).

\section{DISCUSSÃO}

Os valores de força da preensão manual após a primeira luta do campeonato foram inferiores aos valores iniciais para atletas dentro das três faixas etárias. Esta variação de força de preensão manual em lutadores de Jiu-Jítsu brasileiro já foi constatada por Andreato et al. ${ }^{10}$ que ao analisarem 35 atletas encontraram diferenças entre os valores obtidos antes e após as lutas. Entretanto, não se verificou diferenças na força de preensão manual pré e pós combate entre as faixas etárias.

Havia expectativa de que, justamente entre os não graduados, a diferença de valores fosse maior. Sugere-se que em detrimento do processo de aprendizado e falta de conhecimento de variedade de técnicas a serem aplicadas nas diversas situações de luta, estes atletas, menos experientes, tendem a utilizar a força de forma mais intensa na tentativa de vencer o combate. ${ }^{7}$

Durante a luta, as pegadas realizadas no dogi ou nas partes do corpo do adversário, para realização das técnicas, demandam repetidas contrações dos músculos flexores do punho, ou contrações isométricas com duração relativamente longa. Estes movimentos demandam resistência muscular localizada e a ineficiência desta capacidade pode comprometer o rendimento do atleta durante combate..$^{4,11}$
Uma possibilidade para o resultado diferente do esperado pode estar relacionada ao fato do aumento do tempo de combate para cada graduação. Em campeonatos oficiais, atletas com faixa branca têm tempo de luta estipulado em cinco minutos, faixa azul são seis minutos e competidores faixa roxa lutam durante sete minutos. ${ }^{12}$ Diante disto, é possível que esta diferença no tempo de luta possa favorecer maiores níveis de fadiga muscular entre os mais graduados.

Aliado ao aspecto do tempo de luta, o fato dos competidores serem divididos em categorias de peso e faixa de graduação, ou seja, lutadores com a mesma graduação e peso similar competem entre si, faz com que o nível técnico seja em grande parte proporcional e diante disto, o condicionamento físico demonstra extrema importância no desfecho do combate. Neste sentido, a capacidade de resistência muscular dos músculos flexores do punho pode ser determinante na luta. 4,10,13

Alguns autores estudaram a influência da força de preensão manual no desempenho de atletas lutadores e verificaram a importância desta variável na determinação de atletas de alto nível. Franchini et al. ${ }^{7}$ verificaram que atletas em nível nacional obtiveram resultados de força superior e maior quantidade de repetição por tempo determinado no movimento de preensão manual comparado a atletas competidores em nível regional. Recentemente, Silva et al. ${ }^{8}$ demonstraram que a resistência de força isométrica medida pela preensão palmar é um importante resultado para diferenciar o rendimento dos competidores de Jiu-Jítsu brasileiro.

Este estudo apresentou algumas limitações, pois não foi possível realizar a coleta de dados com todos os atletas convidados, por consequência, a amostra foi menor do que a esperada. Entretanto, ainda assim foi possível mais de $50 \%$ dos lutadores inscritos nas categorias selecionadas para o estudo. Devido à diminuição de atletas competidores de acordo com o aumento de graduação, não foi possível investigar a força de preensão manual em atletas de faixa marrom e preta. Possivelmente seria possível apresentar resultados ampliados quanto à diferença de rendimento desta variável entre as graduações. $O$ destaque no estudo foi a realização da 
pesquisa com atletas no ambiente da competição mais importante do estado do Paraná, sendo que uma das dificuldades em pesquisas desta natureza é conseguir amostras durante a competição.

\section{CONSIDERAÇÕES FINAIS}

Foi possível constatar neste estudo diferenças importantes na força de preensão manual antes a imediatamente após combate de atletas lutadores de Jiu-Jitsu brasileiro, graduados nas faixas azul e roxa. O mesmo não ocorreu com lutadores não graduados (faixa branca).

A variação da força de preensão manual foi mais elevada de acordo com aumento da graduação dos atletas, independente da faixa etária do atleta. Diante disto, este estudo sugere que independentemente do aumento do nível técnico dos lutadores, a demanda de capacidades físicas, como a força de preensão manual também se eleva. Assim, possivelmente, estas capacidades poderiam determinar os desfechos dos combates.

\section{REFERÊNCIAS}

1. Novack LF, Salgueirosa FM, Carignano LF, Fornaziero A, Gomes EB, Osiecki R. Distribuição de subgrupos com base nas respostas fisiológicas em jogadores profissionais de futebol pela técnica K Means Cluster. Rev Bras Med Esporte 2013; 19(2): 130-133. DOI: http://dx.doi.org/10.1590/S151786922013000200012.

2. Nunes $A V$, Rubio K. As origens do judô brasileiro: a árvore genealógica dos medalhistas olímpicos. Rev Bras Educ Fís Esporte 2012; 26(4): 667-78. DOI: http://dx.doi.org/10.1590/ S1807-55092012000400011.

3. Meira TB, Bastos FC, Böhme MTS. Análise da estrutura organizacional do esporte de rendimento no Brasil: um estudo preliminar. Rev Bras Educ Fís Esporte 2012; 26(2): 251-62. DOI: http://dx.doi.org/10.1590/S1807-55092012000200008.

4. Bishop SH, Bouty $\mathrm{PL}$, Devlin M. Mixed martial arts: a comprehensive review. J Sport Hum Perf 2013; 1(1): 28-42.

5. Gracie, R. Carlos Gracie: $O$ criador de uma dinastia. $1^{\text {a }}$ edição, Record, 2008.

6. Borges Júnior NG, Gomes Domenech SC, Silva ACK, Jonathan A, Sagawa Junior Y. Estudo comparativo da força de preensão isométrica máxima em diferentes modalidades esportivas. Rev Bras Cineantropom Desemp Hum 2009; 11(3): 292-298.

7. Franchini E, Miarka B, Matheus L, Vecchio FBD. Endurance in judogi grip strength tests: comparison between elite and non-elite judo players. Arch budo 2011; 7(1): 1-4

8. Silva BVC, Marocolo Júnior M, Rogério FC, Dias IS, Simim MAM, Mota GR. Testes físicos discriminam praticantes de Brazilian Jiu-Jitsu? - Rev Bras de Ci Mov 2014; 22(1): 90-96.

9. La Bounty P, Campbell BL, Galvan E, Cooke M, Antonio J. Strength and Conditioning Considerations for Mixed Martial Arts. Strength Cond J 2011; 33(1): 56-67.

10. Andreato LV, Moraes SMF, Gomes TLM, Esteves JVDC, Andreato TV, Franchini E. Estimated aerobic power, muscular strength and flexibility in elite Brazilian Jiu-Jitsu athletes. Sci Sports 2011; 26(6): 329-337. DOI: http://dx.doi.org/10.1016/j. scispo.2010.12.015.

11. Moreira D, Álvarez RRA, Gogoy JR, Cambraia AN. Abordagem sobre preensão palmar utilizando o dinamômetro JAMAR $^{\circledR}$ : uma revisão de literatura. Rev Bras Ci Mov 2003; 11(2): 95-99.

12. IBJJF. International Brazilian Jiu Jitsu Federation. Livro de regras regulamento geral de competições manual de formatação de competições. IBJJF. Rio de Janeiro, Brasil, Janeiro, 2013.

13. Oliveira M, Moreira D, Godoy JRP, Cambraia AN. Avaliação da força de preensão palmar em atletas de jiu-jitsu de nível competitivo. Rev Bras Ci Mov 2006; 14(3): 63-70. 